\section{$\underset{\substack{\text { hommes } \\ \text { \& migrations }}}{ }$}

\section{Hommes \& migrations}

Revue française de référence sur les dynamiques

migratoires

1323 | 2018

Persona grata

\title{
Neuilly sa mère, sa mère !
}

Film, France, 2018, de Gabriel Julien-Laferrière

\section{Mouloud Mimoun}

\section{(2) OpenEdition \\ 1 Journals}

\section{Édition électronique}

URL : https://journals.openedition.org/hommesmigrations/7854

DOI : 10.4000/hommesmigrations. 7854

ISSN : 2262-3353

\section{Éditeur}

Musée national de l'histoire de l'immigration

\section{Édition imprimée}

Date de publication : 1 octobre 2018

Pagination : 206-207

ISBN : 978-2-919040-42-1

ISSN : 1142-852X

\section{Référence électronique}

Mouloud Mimoun, « Neuilly sa mère, sa mère! », Hommes \& migrations [En ligne], 1323 | 2018, mis en ligne le 01 octobre 2018, consulté le 08 janvier 2022. URL : http://journals.openedition.org/

hommesmigrations/7854; DOI : https://doi.org/10.4000/hommesmigrations.7854 


\section{Films}

\section{Neuilly sa mère, sa mère!}

Film de

Gabriel Julien-Laferrière

(France, 2018)

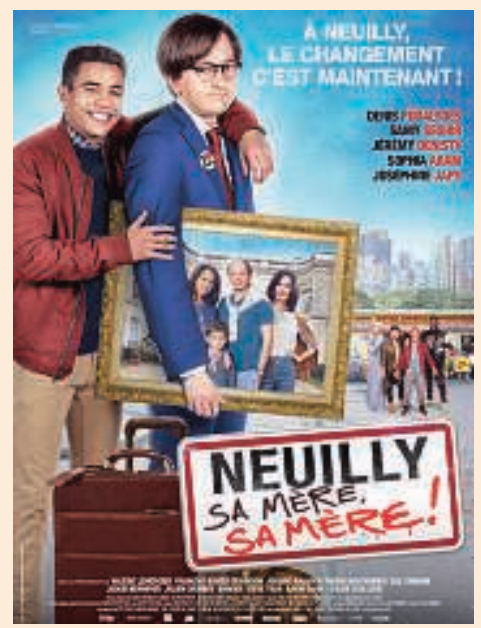

En 2008, il y a eu Neuilly sa mère!, dans lequel Djamel Bensalah, franco-algérien originaire de la Seine-Saint-Denis, fait découvrir au jeune banlieusard Sami Benboudaoud (Samy Seghir) l'enfer de Neuilly-sur-Seine. Dix ans plus tard, en 2018, Bensalah et son complice Gabriel Julien-Laferrière ont concocté une suite qui inverse les rôles et les lieux. Dans Neuilly 
sa mère !, c'est le petit Sami qui découvrait le monde des riches en quittant sa cité de Picasso de Nanterre... Dans ce deuxième opus, Bensalah nous fait faire le chemin inverse. Cette fois c'est la famille française de Neuilly - Bruno Podalydès le père, Sophia Aram son épouse et surtout le fils Charles (remarquable Jérémy Denisty) - qui déménage à Nanterre en milieu HLM suite à des revers de fortune. Le premier Neuilly sa mère ! fut, en son temps, un succès commercial et critique surprenant et nul doute que cette suite est programmée également pour la réussite publique tant les ingrédients de scénario, aussi ingénieux les uns que les autres, entremêlent une intrigue dont la progression comico-dramatique fonctionne parfaitement.

De fait, la démarche cinématographique de Djamel Bensalah, dès ses débuts en 1996, et surtout avec Le ciel, les oiseaux et... ta mère!, son premier long métrage, consiste à mettre en interface des communautés et des milieux sociaux différents. Son credo, c'est de prendre le contrepied de films comme La Haine de Kassovitz ou Ma 6-T va crack-er de Jean-François Richet pour modifier radicalement l'image des quartiers de banlieues qu'il analyse du point de vue de la comédie sociale qu'il maîtrise avec talent. « Ces films coups de poing, majeurs, montraient des banlieues à l'avenir sombre et sans perspectives, je décidais alors d'y opposer une autre vision, plus drôle, plus colorée, loin du bitume et sous le soleil de Biarritz », déclarait Bensalah à propos de Le ciel, les oiseaux et... ta mère !.

Dans Neuilly sa mère, sa mère! on retrouve bien sûr le jeune Sami Benboudaoud qui termine brillamment ses études de sciences politiques tandis que rien ne va plus du côté de son cousin Charles de Chazelles, sarkoziste comme on est tintinophile ... Désespéré par la défaite de son idole en 2012 face à François Hollande, il rêve toujours de devenir président de la République, mais un président de droite!

À Nanterre, il va tenter, sans succès, de supplanter l'élu de droite pour la campagne des municipales... En fait, l'idéologie l'indiffère et les circonstances rocambolesques de son parcours politique le font atterrir candidat... du parti socialiste où sa jeunesse est adoubée par Julien Dray dans son propre rôle. Il côtoie un certain Dupont (incarné par Fatsah Bouyahmed, l'inoubliable héros de La Vache) qui roule pour le Front national, perruque blonde sur la tête en reniant ses origines arabes, et qui a rebaptisé sa fille... France! Charles va créer la surprise et se faire élire maire socialiste haut la main, à force de fausses promesses et de démagogie. II a pris le pli des politiciens..

La force du film réside aussi dans une galerie de portraits où foisonnent des personnages divers qui composent une mosaïque étonnante, laquelle va des jeunes du quartier (Booder en Malik, Bayou Sarr en Sekou et Steve Tran en...Tran) jusqu'au personnel politique en passant par les figures marquantes du quartier (Biyouna entre autres). Le récit avance avec rythme et rigueur, la mise en scène est à la hauteur du propos et le label comédie fonctionne à merveille. Neuilly sa mère, sa mère! est une réussite sur tous les plans, qu'il s'agisse du scénario déjà évoqué, des dialogues ou de la direction d'acteurs très pertinente! M. M. 